\title{
Gestão participativa e padronização em espaços pedagógicos: percepção dos integrantes de uma instituição de educação profissional e tecnológica
}

\author{
Participatory management and standardization in pedagogical \\ spaces: perceptions of members of a professional and \\ technological institution
}

Nieysila Simara da Silva Castro Borges ${ }^{1}$

Ronison Oliveira da Silva ${ }^{2}$

Daniel Nascimento-e-Silva ${ }^{3}$

\section{Resumo}

A padronização é um processo imperativo para a formação com qualidade de profissionais e também para o alcance dos objetivos organizacionais. É necessário que cada etapa do processo se revista de caráter participativo nos espaços pedagógicos. Isso quer dizer que, para que a gestão possa ser considerada participativa, o seu processo de padronização também precisa passar pelo crivo da participação. Este estudo tem como finalidade analisar se o processo de padronização praticado pelos membros de um espaço pedagógico de uma instituição de educação profissional e tecnológica pode

\footnotetext{
${ }^{1}$ Mestra em Educação Profissional e Tecnológica pelo IFAM (2019). Licenciada em Pedagogia pela Universidade Federal do Maranhão (2007) e Especialização em Docência da Educação Básica e Superior pela Faculdade de Teologia Hokemah (2014) e em Psicologia da Educação pela UEMA (2017). Atou desde 2015 como Pedagoga do IFMA Campus Grajaú. Atualmente encontra-se lotada no IFMA Campus Açailândia.

${ }^{2}$ Administrador. Especialista em Gerenciamento de Projetos. Discente do Mestrado em Educação Profissional e Tecnológica (ProfEPT) no Instituto Federal do Amazonas - IFAM Campus Manaus Centro.

${ }^{3}$ Possui graduação em Administração pela Universidade Federal do Pará (1990), mestrado em Administração pela Universidade Federal de Santa Catarina (1995) e doutorado em Engenharia de Produção pela Universidade Federal de Santa Catarina (2002). Atualmente é professor do Instituto Federal de Educação, Ciência e Tecnologia do Amazonas
}

Interfaces da Educ., Paranaíba, v.11, n.32, p. 79 - 105, 2020 
ser considerado participativo. É um estudo qualitativo, desenvolvido a partir do método pesquisa de campo, com unidade de análise individual, nível de análise organizacional e perspectiva de análise sincrônica, cujos dados foram coletados através de entrevista estruturada. Foi testada a hipótese de que os membros do espaço pedagógico participam de todas as fases de padronização e que, por esse motivo, o processo é participativo. Os resultados descartaram a hipótese inicial, nula, levando à adoção da hipótese alternativa, de que o espaço não pode ser considerado participativo, uma vez que nem todos os seus membros participam de todas as etapas do processo de padronização. A conclusão apresentada mostra que, no máximo, há etapas semiparticipativas nas etapas do processo analisado.

Palavras-chave: Padronização. Participação. Espaço Pedagógico.

\section{Abstract}

Standardization is an imperative process for quality training of members and for the achievement of organizational objectives. It is necessary that each stage of the process reveals a participatory character in the pedagogical spaces. This means that for management to be considered participatory, its standardization process must also be screened for participation. This study aims to analyze whether the standardization process practiced by members of a pedagogical space of a vocational and technological education institution can be considered participatory. It is a qualitative study, developed from the field research method, with individual analysis unit, organizational analysis level and synchronic analysis perspective, whose data were collected through structured interview. The hypothesis that the members of the pedagogical space participate in all phases of standardization was tested and, therefore, the process is participatory. The results discarded the initial null hypothesis, leading to the adoption of the alternative hypothesis that space cannot be considered participative, since not all its members participate in all stages of Interfaces da Educ., Paranaíba, v.11, n.32, p. 79 - 105, 2020 
the standardization process. The conclusion presented shows that, at most, there are semi-participatory steps in the steps of the analyzed process.

Keywords: Standardization. Participation. Pedagogical Space.

\section{Introdução}

Os espaços pedagógicos se encontram com os desafios quase que diários de criar e encontrar padrões e muitas vezes o fazem sem saber que existem técnicas para isso. A finalidade desses procedimentos e técnicas é, ao mesmo tempo em que assegura a qualidade daquilo que se está fazendo, reduzir os custos dessas operações (TUCZEK; CASTKA; WAKOLBINGER, 2018; LAPCHAK; ZHANG, 2018; GARDNER; LINDERMAN; MCFADDEN, 2018; MOSCHIDIS; CHATZIPETROU; TSIOTRAS, 2018). O desafio de todo esforço de padronização é sempre fazer o melhor possivel aquilo que se dispõe a fazer. E isso vale, sobretudo, para o processo educativo e seu desafio maior, a aprendizagem.

Não se criam padrões, consequentemente, porque se quer controlar a vida e a mente das pessoas, como muitos podem, erroneamente, imaginar. Os padrões existem para facilitar e organizar a vida e a mente das pessoas. É com base nos padrões, por exemplo, que cada docente assegura que determinado aluno não obteve o rendimento necessário para ser aprovado ou que um conselho de classe tem a convicção de que outro aluno pode ser considerado um gênio. Os padrões servem para isso: para nos ajudar a ver o mundo com mais clareza.

Não é dificil perceber, portanto, que praticamente toda gestão participativa só é assim considerada porque está assentada sobre padrões coletivamente construídos e institucionalizados, como sugerem os estudos de Somers (2018), Zhu e Warner (2018) e Molinéro-Demilly e colaboradores (2018), dentre inúmeros outros. Isso significa que, em determinado espaço de aprendizagem, são os membros organizacionais que definem os padrões, Interfaces da Educ., Paranaíba, v.11, n.32, p. 79 - 105, 2020 
seguem esses padrões, avaliam a validade deles e os modificam ou os substituem, quando isso se fizer necessário. É com base nos padrões, portanto, que definimos se uma instituição ou espaço pedagógico é gerenciado de forma participativa ou não.

Este estudo tem como finalidade analisar se o processo de padronização praticado pelos membros de um espaço pedagógico de uma instituição de educação profissional e tecnológica pode ser considerado participativo. Como os estudos sobre padronização ainda são carentes nas organizações educacionais brasileiras e muito mais ainda em relação ao gerenciamento dos nossos espaços pedagógicos, a criação deste modelo em muito vai facilitar tanto o entendimento do que é gestão participativa quanto das etapas do processo de padronização que podem ser utilizados na prática para gerar padrões consensualmente aceitos pelos indivíduos.

Dessa forma, a contribuição que esta investigação pretende dar para a área de gestão de espaços pedagógicos é: a adoção de um modelo teóricoempírico capaz de assegurar a prática da gestão participativa na criação de padrões organizacionais, ao mesmo tempo em que colabora com a expansão das fronteiras do conhecimento gerencial nesse tipo específico de organização.

\section{Gestão participativa e padronização}

Gestão é o processo de planejar, organizar, dirigir e controlar recursos para o alcance dos objetivos organizacionais, enquanto que uma organização é o agrupamento de pelo menos duas pessoas com o intuito de alcançar objetivos previamente combinados entre elas (NASCIMENTO-E-SILVA et al., 2013; NASCIMENTO-E-SILVA, 2016). Sendo os espaços pedagógicos um tipo de organização, uma vez que são compostos pelo menos de um instrutor e um aluno ou aprendiz, o processo gerencial também a eles se aplica. Dessa forma, os espaços pedagógicos precisam planejar, organizar, dirigir e controlar seus recursos para que os objetivos de aprendizagem possam se materializar.

Interfaces da Educ., Paranaíba, v.11, n.32, p. 79 - 105, 2020 
Uma das etapas do processo gerencial é a função controle (SILVA et al., 2019). Esta função tem como finalidade garantir que os objetivos definidos sejam materializados a partir do uso de certos recursos utilizados na execução de uma ou mais estratégias, que são formas de fazer o que tem que ser feito, de materialização de objetivos. Assim, o foco de atenção do processo de controle são o consumo dos recursos ao longo das etapas do processo. Isso significa que não se controlam pessoas, são as pessoas que controlam os processos de produção e os atributos (características) dos produtos, que são todo tipo de saídas de um sistema de produção.

O foco do controle é a qualidade do produto e a eficiência de cada etapa do processo de produção. Nos espaços pedagógicos, o foco do controle é a aprendizagem e o uso dos recursos em cada etapa do processo de aprendizagem. Para que isso aconteça de forma adequada, tecnicamente a função controle funciona com base em quatro etapas. A primeira é a padronização, que é a especificação do produto; a segunda é a mensuração, que é a mensuração da especificação do produto; a terceira é a avaliação, que é a comparação do resultado da mensuração com o padrão definido; e a quarta é o replanejamento, que é uma sistemática de correção de falhas e defeitos tanto no produto quanto no processo de produção (NASCIMENTO-ESILVA et al., 2013).

Alguns autores destacam a importância do processo de padronização para o aperfeiçoamento das atividades desenvolvidas por uma organização. Dal Forno e colaboradores (2014) dizem que a padronização estabelece bases para o desenvolvimento de melhores práticas. Wiemes e Balbinotti (2011) entendem que a padronização é uma atividade que favorece a correta realização de um procedimento, levando-o à excelência. Disso depreende-se que sem o estabelecimento de parâmetros para a realização de uma atividade fica difícil executá-la com precisão. Não basta saber o que se deve fazer; é preciso saber como fazer, ou melhor, é preciso saber a melhor forma de se fazer. 
Piccoli e Prado 2018), por sua vez, destacam a padronização de um processo como uma ferramenta para reduzir a variabilidade das informações, tornando-as confiáveis para uso em processos decisórios e de planejamento. Diante disso, pode-se inferir que a padronização favorece a elaboração de um conhecimento sólido acerca dos processos e procedimentos desenvolvidos pela organização, permitindo o registro e a compreensão da dinâmica organizacional. Essa compreensão é fundamental para perceber acertos e imprecisões e aperfeiçoar a prática.

Em gestão de espaços pedagógicos praticamente todo tipo de teste ou avaliação apresenta pelo menos um padrão a ser seguido para que os desses testes e avaliações, tecnicamente chamados resultados, possam ser conhecidos. Há, portanto, teste de desempenho didático, avaliação de projetos pedagógicos, planos de ensino, avaliação de desempenho, avaliação de trabalhos escolares e dai por diante. Isso quer dizer que, onde houver avaliação, ali terá, necessariamente, um padrão a ser seguido. É o padrão que permite dizer se algo está ou não adequado. Sem padrão, portanto, não há gestão e nem educação.

Uma série de ocorrências institucionais levam à necessidade de padronizar processos ou produtos. Exemplos dessas ocorrências são custos elevados, baixo desempenho do pessoal, baixa qualidade do ensino e da formação profissional, baixa imagem da instituição no ambiente, dificuldades de alcançar objetivos e expansão, dificuldades em alcançar niveis normais de eficiência, dentre inúmeros outros.

Quadro 1. Etapas do processo de padronização

\begin{tabular}{|l|l|}
\hline \multicolumn{1}{|c|}{ Etapa } & \multicolumn{1}{c|}{ Conteúdo } \\
\hline $\begin{array}{l}\text { Identificação do } \\
\text { processo }\end{array}$ & $\begin{array}{l}\text { Fase onde são detalhados os motivos que levaram à } \\
\text { necessidade de padronização. }\end{array}$ \\
\hline $\begin{array}{l}\text { Elaboração dos } \\
\text { padrões }\end{array}$ & $\begin{array}{l}\text { Aqui as várias alternativas de padronização são } \\
\text { apresentadas e escolhida a mais viável. }\end{array}$ \\
\hline Validação dos & É a fase de testes e ajustes até que os padrões estejam \\
\hline
\end{tabular}

Interfaces da Educ., Paranaíba, v.11, n.32, p. 79 - 105, 2020 


\begin{tabular}{|l|l|}
\hline padrões & em conformidade com o esperado. \\
\hline Treinamento & $\begin{array}{l}\text { Fase de ensino do uso dos padrões a toda a } \\
\text { comunidade. }\end{array}$ \\
\hline $\begin{array}{l}\text { Implantação dos } \\
\text { padrões }\end{array}$ & Etapa da adoção institucional dos padrões. \\
\hline Acompanhamento & Monitoramento do uso adequado dos padrões. \\
\hline
\end{tabular}

Fonte: Elaborado pelos autores (2019).

Com base nos estudos de Andrade (2004), Netto e Medeiros (2015), Nyúl e Udupa (1999) e Sengoku et al. (2011), este estudo considera como etapas que normalmente são percorridas para gerar um padrão são: a) identificação do processo a ser padronizado, b) elaboração dos padrões, c) validação dos padrões, d) treinamento sobre o uso dos padrões, e finaliza com a fase e) acompanhamento da execução. O quadro 1 especifica o conteúdo de cada parte específica. Essas etapas começam com a detectação dos motivos que forcem a padronização de algum processo e culminam com o uso dos padrões criados e seu devido acompanhamento por toda a coletividade, de modo que aqueles motivos que ensejaram a padronização sejam eliminados ou amenizados.

Assim, a padronização é o processo que permite estabelecer parâmetros confiáveis para o desenvolvimento satisfatório de uma ação ou procedimento. Isso significa que a padronização é o processo que determina os padrões para os procedimentos a serem desenvolvidos dentro de uma organização. Esta etapa da função controle é considerada, portanto, uma importante ferramenta gerencial de aperfeiçoamento das atividades executadas em uma organização e minimização de custos e imprecisões.

Sendo a padronização um processo imperativo para a formação com qualidade de profissionais e para o alcance dos objetivos organizacionais, é necessário que cada etapa da escolha dos padrões se revista de caráter participativo nos espaços pedagógicos. Isso quer dizer que, para que a gestão possa ser considerada participativa, o seu processo de padronização também Interfaces da Educ., Paranaíba, v.11, n.32, p. 79 - 105, 2020 
precisa passar pelo crivo da participação. Como os padrões precisam ser conhecidos por todos, todos precisam fazer parte das suas escolhas, principalmente aqueles que terão que lidar com os processos de mensuração, avaliação e replanejamento.

A participação pode ser definida como o processo pelo qual membros de uma organização deliberam e executam ações (KUDO; PEREIRA; SILVA, 2016; LOUSÃO, 2009; FERNANDES, 2015), sem desconsiderar, contudo, as responsabilidades que precisam ter para com os resultados auferidos. Dessa forma, a participação é percebida como uma prática social que envolve todos os membros de um grupo na tomada de decisão, assim como na execução e responsabilização pelas ações. Quando parte do grupo é excluída de uma dessas etapas a participação não acontece plenamente.

Nesse sentido, a participação pressupõe um processo de construção coletiva que mobiliza os sujeitos para decidir, defender valores e interesses e agir em torno de práticas equitativas. Essa compreensão permite identificar os níveis de participação de cada membro em cada prática e processo desenvolvido nas instituições das quais fazem parte. No contexto das instituições educacionais tem-se percebido a necessidade da implementação de práticas mais participativas nos processos de gestão e ensino, principalmente no aspecto da padronização, que é condição necessária muitas vezes incompreendida, principalmente por quem não tem formação em gestão.

O desenvolvimento de processos participativos no âmbito das instituições de ensino é uma tarefa complexa e muitas vezes conflitante, que envolve múltiplos sujeitos, visto que diz respeito ao exercício de práticas democráticas, as quais requerem esforço e resiliência. Dessa forma, é provável que, quanto mais pessoas participam, mais dificil e conflitante será o processo decisório (LOUSÃO, 2009). Essa constatação leva à percepção de que a participação de muitas pessoas nas deliberações de questões importantes para o grupo requer habilidades relacionais (LOUSÃO, 2009) e cuidados para que o resultado final congregue a sintese de interesses Interfaces da Educ., Paranaíba, v.11, n.32, p. 79 - 105, 2020 
diversos que, na maioria das vezes, os gestores das instituições educacionais não as têm.

Quanto aos tipos de participação podemos classificar a participação quanto aos níveis em: não participação, participação moderada e alta participação ou ação coletiva (poder de cidadão) (CARVALHO; RODRIGUES, 2018; RIBEIRO, 2018). A não participação consiste em um tipo de participação passiva do sujeito, em que ele é manipulado por terceiros. A participação moderada ou média participação diz respeito aos processos de participação envolvendo consulta ou levantamento de informações. A alta participação ou poder do cidadão é quando o sujeito alcança níveis elevados de engajamento político e age em benefício da coletividade (CARVALHO; RODRIGUES, 2018; RIBEIRO, 2018). Dessa forma, podemos classificar os tipos de participação de acordo com o nível de intensidade de participação dos sujeitos nos processos, ou melhor, podemos organizar os tipos a partir do envolvimento ativo ou passivo dos sujeitos em determinada ação ou processo.

Ribeiro (2018) destaca a importância dos tipos de participação ativa ressaltando vantagens e desvantagens. Dentre as vantagens, por meio da participação ativa são recolhidas as opiniões dos cidadãos e se tem um processo mais transparente; dentre as desvantagens está a demanda elevada de tempo, problemas de liderança, elevação demasiada dos custos e desinteresse dos participantes.

Assim, a participação é uma prática social que envolve todos os membros de um grupo na tomada de decisão, execução e responsabilização pelas ações (KUDO, MALTA, FERNANDES, 2016). Só é caracterizada como prática participativa a ação que envolve a participação de todos os sujeitos de uma organização em cada uma dessas etapas, que dão lugar aos tipos de participação. Os tipos de participação podem ser classificados em não participação, participação moderada e alta participação ou ação coletiva (poder do cidadão) (CARVALHO, RODRIGUES, RIBEIRO, 2018). O processo 
de participação, segundo os autores, acontece inicialmente pela detecção, seguido da etapa de preparação, definição de proposta e acompanhamento.

Quadro 2. Etapas do processo de participação

\begin{tabular}{|l|l|}
\hline \multicolumn{1}{|c|}{ Etapa } & \multicolumn{1}{c|}{ Caracteristica empirica } \\
\hline Tomada de consciência & $\begin{array}{l}\text { É quando o indivíduo ou grupo percebe que é o } \\
\text { momento de participar }\end{array}$ \\
\hline $\begin{array}{l}\text { Preparação da } \\
\text { participação }\end{array}$ & $\begin{array}{l}\text { É a articulação psíquica ou grupal sobre a maneira } \\
\text { de participar e lidar com a situação }\end{array}$ \\
\hline Decisão & $\begin{array}{l}\text { É a apresentação e tomada de decisão do grupo } \\
\text { acerca da solução mais viável para a situação }\end{array}$ \\
\hline $\begin{array}{l}\text { Acompanhamento da } \\
\text { execução }\end{array}$ & $\begin{array}{l}\text { É a comparação contínua do que foi decidido e do } \\
\text { que está sendo realizado }\end{array}$ \\
\hline
\end{tabular}

Fonte: Elaborado pelos autores (2019).

A fase inicial de detecção consiste no momento que o grupo toma consciência da necessidade da participação, que pode advir pela informação oficial recebida ou informalmente obtida, mas que pode efetivamente participar; se não for possível, não será considerada participação para este estudo. A segunda fase, a de preparação, é o momento em que se estabelecem as estratégias de participação, identifica-se a situação problema e passa-se para terceira etapa que consiste na decisão da proposta mais viável para solucionar o problema identificado (CAIXETA; FABRICIO, 2018) e o seu necessário acompanhamento (SABIONI; FERREIRA; REIS, 2018). Obviamente, cada processo participativo tem suas peculiaridades, mas podese compreender que o momento inicial se dá com a mobilização em torno de uma situação problema e avança para a ação coletiva em torno da resolução. Esse processo vai adquirindo legitimidade à medida que mais pessoas se envolvem no processo de tomada de decisão e execução das propostas.

Dessa forma, para efeitos deste estudo, serão consideradas as seguintes etapas para o processo de participação na gestão dos espaços pedagógicos, conforme mostra, sinteticamente, o quadro 2: primeira, tomada Interfaces da Educ., Paranaíba, v.11, n.32, p. 79 - 105, 2020 
de consciência da necessidade de participar, geralmente ocorre quando o indivíduo ou grupo percebe ou é informado sobre a necessidade de lidar com determinado problema que está causando ou venha a causar algum tipo de influência sobre ele; a segunda é a preparação, que corresponde à busca de solução para a situação, seja individual ou coletivamente, para ser apresentado para todos os membros do grupo; a terceira etapa é a definição da proposta, onde as soluções são apresentadas e o grupo escolhe a que considera mais viável para a situação; e a quarta e última etapa é o acompanhamento da execução, cuja finalidade é verificar, de forma contínua, se aquilo que foi decidido está sendo implementado.

Quadro 3. Evidências empíricas para o processo de padronização participativo

\begin{tabular}{|l|l|}
\hline \multicolumn{1}{|c|}{ Etapa } & \multicolumn{1}{c|}{ Evidência empirica } \\
\hline $\begin{array}{l}\text { Identificação do } \\
\text { processo }\end{array}$ & $\begin{array}{l}\text { É quando o indivíduo ou grupo percebe que é o } \\
\text { momento de participar }\end{array}$ \\
\hline $\begin{array}{l}\text { Elaboração dos } \\
\text { padrões }\end{array}$ & Debateu ou criou os padrões? \\
\hline Validação dos padrões & Validou ou acompanhou a validação? \\
\hline Treinamento & Foi treinado ou treinou usuários? \\
\hline $\begin{array}{l}\text { Implantação dos } \\
\text { padrões }\end{array}$ & Usou ou ajudou a usar os padrões? \\
\hline Acompanhamento & Acompanhou a execução? \\
\hline
\end{tabular}

Fonte: Elaborado pelos autores (2019).

O modelo teórico deste estudo consiste na análise da forma de participação dos membros de determinado espaço pedagógico em relação a cada etapa do processo de padronização. A hipótese central do estudo é que todos os membros daquele espaço participam de todas as fases de padronização e que, por esse motivo, o processo é participativo. A hipótese alternativa diz que poucas pessoas participam e o fazem apenas em relação Interfaces da Educ., Paranaíba, v.11, n.32, p. 79 - 105, 2020 
a algumas etapas do processo de participação, configurando o gerenciamento não participativo. As evidências empíricas para o estudo, como mostra o conteúdo do quadro 3 , serão coletadas a partir da participação dos membros do espaço de aprendizado em todas as etapas do processo de padronização. Quanto mais membros participarem do maior número de etapas, maior a participação na gestão institucional.

\section{Metodologia}

A estratégia metodológica utilizada para a realização desta investigação consistiu no levantamento empírico de dados e informações que permitisse avaliar se cada etapa do processo de padronização praticado em determinado espaço pedagógico de uma instituição de educação profissional e tecnológico pode ou não ser considerado participativo. Essa estratégia encontra-se detalhada nesta seção.

\section{Caracteristicas da pesquisa}

Esta pesquisa se caracteriza por ser eminentemente qualitativa. Utilizou o método de Levantamento, cuja finalidade é gerar explicação para determinada população a partir do estudo de uma amostra. Teve como unidade de análise a percepção de quatro membros de determinado espaço pedagógico (unidade de análise individual) para gerar explicações de ordem organizacional, que é como é considerado o ambiente de aprendizado estudado (nível de análise organizacional). Assim, teve-se unidade de análise individual e nível de análise interorganizacional (NASCIMENTO-E-SILVA, 2012). A perspectiva de análise foi sincrônica, uma vez que a explicação gerada diz respeito a uma realidade tomada em posição estática, como uma fotografia, diferentemente da perspectiva diacrônica, que caracteriza os estudos longitudinais (NASCIMENTO-E-SILVA et al., 2013). 


\section{Sujeitos, população e amostragem}

A população deste estudo foi constituída por todos os indivíduos que fazem parte do espaço pedagógico estudado, que foi o laboratório de Informática de uma determinada instituição de educação profissional e tecnológica da Região Nordeste do Brasil. Portanto, a característica da população do estudo foi essa: ser membro do espaço pedagógico estudado com participação mínima de doze (12) meses que o integra. Foram escolhidos como sujeitos desta pesquisa quatro membros daquele espaço. Optou-se pela amostragem por conveniência, cujo requisito principal foi conhecer com profundidade as regras e normas de utilização do espaço analisado. A aplicação desse procedimento gerou como amostra um aluno (AL) estudante do $2^{\circ}$ ano, um professor (PR) que atua na instituição há vinte e quatro (24) meses, um técnico em informática (TI1) que atua na instituição há vinte e quatro (24) meses, e um técnico de laboratório (TI2) que atua na instituição há dezoito (18) meses.

\section{Estratégia de coleta e organização dos dados}

A coleta de dados contou com a colaboração dos quatro individuos resultantes do processo de amostram. Todos foram contatados para agendamento da entrevista, que ocorreu com o auxílio de um roteiro previamente enviado a cada um deles, para que se preparassem adequadamente. No dia aprazado, foram feitas as coletas de dados e informações relativas a: a) ao processo de padronização de que participou, b) elaboração, c) validação dos padrões, d) treinamento sobre os padrões, e) implantação dos padrões e f) acompanhamento do uso dos padrões. As respostas foram gravadas, com autorização de cada respondente.

Depois de coletados, os dados foram digitados em planilha eletrônica. Esse procedimento permitiu que se reunissem e fossem colocadas lado a lado todas as respostas para a mesma pergunta. Assim, foram gerados cinco blocos de respostas, cada qual relacionada com as questões norteadoras do estudo, coincidentes com as etapas do processo de participação que Interfaces da Educ., Paranaíba, v.11, n.32, p. 79 - 105, 2020 
estruturaram teoricamente o estudo. Isso permitiu que fossem identificadas semelhanças e diferenças entre as respostas, de maneira que se pudesse analisá-las com adequação.

\section{Análise e interpretação dos dados}

Os dados foram analisados a partir de um esquema do tipo "Sim" e "Não". Por exemplo, para a primeira questão "O respondente participou da elaboração dos padrões?", cada resposta de cada respondente correspondeu a um e somente um "Sim" ou "Não". Os resultados foram gerados da seguinte forma: a) quando todos os respondentes responderam "Sim", a etapa do processo foi considerada participativa; b) quando a maioria 2 ou mais dos respondentes respondiam "Sim", a etapa foi considerada semiparticipativas; e c) quando 1 ou ninguém respondeu "Sim", a fase foi catalogada como não participativa.

Cada resultado foi interpretado da seguinte forma. Primeiro foi analisado o conjunto de respostas de cada respondente para cada etapa, para que se compreendessem os fundamentos do resultado encontrado individualmente e, em seguida, em grupo, de maneira que se pudesse entender a lógica explicativa de cada achado. Essa lógica foi, então, comparada com os fundamentos teóricos do estudo, para que se pudesse localizá-las teórico-empiricamente.

\section{Limitações do estudo}

Duas são as limitações deste estudo, mas que não invalidam os seus resultados. A primeira é relativa à amostra e ao procedimento de amostragem. As amostras intencionais são necessárias para que se compreenda com profundidade o comportamento de determinado fenômeno, no caso deste estudo, a participação nos procedimentos de padronização. Da mesma forma que a amostragem intencional, que gera amostra pequena, permite profundidade compreensiva, também perde em generalidade. Talvez amostras grandes (mais de 40 respondentes) pudessem trazer resultados Interfaces da Educ., Paranaíba, v.11, n.32, p. 79 - 105, 2020 
diferentes, mas impediriam a profundidade compreensiva obtida. Isso significa que se obteve compreensão profunda da participação naquele espaço pedagógico, mas com a restrição de que esses resultados não podem ser generalizados.

A segunda é relativa horizonte temporal transversal. Relatos de fatos passados podem gerar ambiguidades, ainda que relativos a distâncias temporais pequenas. Ainda que o cruzamento de informações, como feito aqui, as reduza ao máximo, há sempre alguma lacuna que não pode ser preenchida porque o cérebro apaga lentamente o que nele é depositado à medida que o tempo passa. E cada recordação é também uma forma de alteração o que nele está depositado. $O$ ideal seria acompanhar temporalmente cada fase de elaboração de padrões, o que é impossivel em relação aos padrões existentes e vigentes.

\section{Resultados}

Nessa seção realizar-se-á a análise e interpretação dos dados a fim de gerar informações úteis e crediveis para a compreensão dos niveis de participação no processo de padronização do espaço pedagógico estudado. Foram analisadas as respostas de cada respondente sobre a participação ou não participação em cada etapa do processo de padronização (identificação do processo, elaboração dos padrões, validação dos padrões, treinamento para os padrões, implantação dos padrões e acompanhamento do padrão). Os entrevistados são membros do espaço pedagógico e foram identificados como TI1, TI2, AL e PR.

\section{Identificação do processo}

A primeira etapa de padronização diz respeito a identificação do processo. Esta fase consiste na identificação dos motivos que germinaram à necessidade de padronização e resulta na utilização dos padrões criados e seu devido acompanhamento por toda a coletividade. Os resultados das entrevistas com os usuários (TI1, TI2, AL e PR) do espaço pedagógico Interfaces da Educ., Paranaíba, v.11, n.32, p. 79 - 105, 2020 
estudado demonstraram que essa etapa inicial não é participativa, pois todos os respondentes não participaram dessa etapa. A etapa inicial da padronização é importante para que o coletivo entenda as demandas que justificam o processo de padronização e definam as ações que serão adotadas para que o gerenciamento do espaço pedagógico aconteça de forma satisfatória.

Os entrevistados expuseram que há um processo de padronização para uso do espaço pedagógico, embora não haja documento sistematizado de comunicação das normas. As normas nem sempre existiram, elas surgiram após a identificação de problemas que interferiam na gestão e organização do espaço pedagógico. A discussão dos problemas identificados não foi feita na coletividade. Verifica-se, em relação a etapa inicial do processo de padronização que as falas de AL, PR, TI e TI2 revelam conhecimento sobre as normas, embora não tenham participado ativamente do processo de identificação e deliberação quanto à necessidade de padronização. Depreende-se, portanto, que na fase inicial o processo não pode ser considerado participativo.

"Não existiam, surgiram depois. Os alunos estavam fazendo mau uso e poderia danificar os periféricos, e o uso da internet também estava prejudicando o rendimento das aulas. Os alunos só foram informados dos problemas e das regras". (AL).

"Não cheguei a participar de nenhuma reunião sobre esse tema, fui informado conforme foram surgindo algumas demandas no laboratório". (TI1).

\footnotetext{
"Então, minha resposta é não. Não fui informado dessa participação para a criação de normas e discussões de problemas sobre o uso desse espaço". (TI2).
}

"Quando cheguei ao Campus essas normas já eram preestabelecidas e repassadas informalmente aos professores. Somente fui informado sobre os mesmos". (PR). 


\section{Elaboração dos padrões}

A segunda etapa de padronização consiste na elaboração dos padrões. Esta fase refere-se a etapa de construção coletiva dos padrões ou normas quanto à gestão e organização do espaço pedagógico. Os resultados revelaram que todos os respondentes não participaram do processo de elaboração dos padrões, observando-se níveis diferentes de participação nessa etapa. AL contribuiu sugerindo a criação de um padrão, $P R$ apenas foi comunicado sobre os padrões, enquanto TI1 e TI2 não foram informados formalmente.

Assim, na elaboração dos padrões não houve participação ativa de todos os respondentes, portanto, nessa etapa o processo também não pode ser considerado participativo. As falas de TI1 e TI2 revelam um nivel de não participação. As falas de $\mathrm{AL}$ e $\mathrm{PR}$ demonstram respectivamente uma participação moderada e uma baixa participação. Como o processo de padronização tem se revelado pouco participativo, não se pode dizer que os padrões foram coletivamente construídos e institucionalizados, embora pareça haver um entendimento coletivo que os padrões são importantes. Muito embora os respondentes tenham conhecimento dos padrões estabelecidos para gerenciamento do espaço pedagógico, depreende-se das falas coletadas que não existe registro ou documento sistematizado que comunique os padrões à comunidade escolar. A legitimidade do processo de padronização pressupõe a participação ampla dos membros da organização na elaboração dos padrões, afinal eles serão responsáveis pela implementação dos padrões.

\footnotetext{
"Os alunos sugeriram apenas a norma quanto ao uso da internet. Durante a aula surgiu esta ideia de usar a internet para fins de aula, pois quando a atividade necessitava do uso da internet tínhamos dificuldades de concluir, devido alguns colegas estarem usando o Youtube e outros". (AL).
}

"Somente fui informado sobre os mesmos". (PR). 
"Não participei ou fui informado formalmente/oficialmente". (TI1).

"Sinceramente, eu não recordo desse processo de elaboração das normas ou de comunicado para tal elaboração, mas acredito que sem normas não tem como funcionar de forma adequada esse espaço educacional". (TI2).

\section{Validação dos padrões}

A validação dos padrões diz respeito a terceira etapa do processo de padronização. É a fase na qual sucessivos testes são realizados até que os padrões estejam em conformidade com o esperado. Os resultados das entrevistas apontaram que todos os respondentes não participaram dessa etapa de validação, bem como do seu acompanhamento. O gerenciamento do espaço pedagógico é feito de acordo com as normas estabelecidas, porém não houve um momento de apreciação e validação do modelo referencial de gerenciamento do espaço.

Em relação a etapa de validação, observa-se que as respostas de AL, T1, T2 e PR indicam uma não participação. Quando um padrão é estabelecido, é preciso discutir com os sujeitos se essa é a melhor solução para aquele problema detectado. Os problemas decorrentes do gerenciamento do espaço pedagógico estudado apontaram para a necessidade de criação de normas com vistas a estabelecer as formas de utilização corretas tanto do espaço como dos equipamentos. Entretanto, não houve uma definição coletiva de qual seria a intervenção mais resolutiva. Assim, sobre a participação no processo de validação da proposta, os respondentes se manifestaram consoante as falas abaixo em destaque:

"Os alunos só foram informados dos problemas e das regras". (AL).

"Quando cheguei no campus essas normas já eram preestabelecidas (sic) e repassadas informalmente aos professores". (PR). 
"Quando cheguei no campus já havia um procedimento adotado entre os professores e alunos e de minha parte não teve nenhuma cooperação em adicionar alguma norma". (TI1).

"Na época eu estava em outro setor, o que me deixa mais fora dessas normas de utilização. Mas o que eu posso ver é que as normas devem ser levadas e tratadas com todos a quem utilizarão (alunos, professores e técnicos), e que mesmo eu em outro setor, deveria saber da existência de discussões sobre o uso do espaço educacional". (TI2).

\section{Treinamento sobre os padrões}

A quarta etapa do processo de padronização equivale a fase de treinamento. Essa fase abrange o ensino do uso de padrões para toda a comunidade. Os resultados demonstraram que todos os respondentes não participaram dessa etapa dos padrões. Observam-se níveis díspares de participação. Quando foram questionados sobre o treinamento, se foram treinados ou treinaram usuários, AL, TI1 e TI2 responderam que não foram treinados e não treinaram usuários, o que configura não participação; enquanto que PR respondeu que participou dessa etapa treinando usuários indicando uma alta participação.

A partir das respostas coletadas, depreende-se que essa fase do processo de padronização não foi participativa. O ensino do uso dos padrões parece um tanto confuso, visto que $\mathrm{AL}$ disse não ter recebido nenhum treinamento, mas PR diz treinar usuários. Os TI's também revelaram não contribuir com o treinamento dos usuários. Outrossim, é possivel inferir que apenas parte dos usuários recebem treinamento para o uso dos padrões. Essa etapa, bem como as anteriores, parece não ser compreendida por toda a comunidade escolar.

"Não fomos treinados". (AL).

"Geralmente o treinamento é repassado aos alunos na disciplina Introdução à Informática, visto que faz parte do conteúdo inicial da disciplina identificação dos equipamentos de informática e manuseio dos mesmos". (PR).

Interfaces da Educ., Paranaíba, v.11, n.32, p. 79 - 105, 2020 
"Ainda não participei de nenhum treinamento referente aos recursos do laboratório de informática nem treinei os usuários do espaço”. (TI1).

“Não, mas posso também mencionar é que há um servidor dedicado somente para esse setor (técnico de laboratório) que podemos solicitar o seu remanejamento para a utilização devida do espaço". (TI2).

\section{Implantação dos padrões}

A quinta etapa de padronização diz respeito a implantação dos padrões. Essa fase consiste na admissão institucional dos padrões para a melhoria do gerenciamento do espaço pedagógico. Os resultados das entrevistas com os usuários demonstram que TI1 e TI1 não participaram da implantação dos padrões, uma vez que não colaboram no processo de apropriação desses padrões; AL se apropria dos padrões para uso do espaço e equipamentos; e PR participou da implantação dos padrões, pois, orienta os usuários quanto ao uso dos padrões. Nota-se que todos os respondentes não participaram desta etapa, apenas AL e PR.

Questionados sobre a apropriação das normas para uso do espaço/equipamentos ou se ajuda outros a utilizarem de acordo com as normas, AL e PR demonstraram alta participação, enquanto TI1 e TI2 revelaram uma não participação nessa etapa. Infere-se que a fase de implantação de padrões foi semiparticipativa, uma vez que não houve mobilização de todos para a efetivação da proposta de padronização. Apenas parte do grupo de respondentes demonstrou algum grau de participação (KUDO; FERNANDES; SILVA, 2016; LOUSÃO, 2009; FERNANDES, 2015) nesta fase específica concernente aos padrões.

“Nos apropriamos durante as aulas." (AL).

"Auxilio os alunos a cumprirem essas orientações durante as aulas." (PR).

Interfaces da Educ., Paranaíba, v.11, n.32, p. 79 - 105, 2020 
"Dentro do possível são aplicadas algumas normas "gerais" de uso dos recursos, porém esses recursos e/ou instruções não são solicitados obrigatoriamente a minha pessoa". (TI1).

“Não, nunca utilizei." (TI2).

\section{Acompanhamento dos padrões}

O acompanhamento do uso dos padrões diz respeito a sexta etapa do processo de padronização. Nessa fase acontece o monitoramento do uso adequado dos padrões no gerenciamento do espaço pedagógico. Verificou-se que nessa etapa, TI1, TI2 e AL não participaram, enquanto PR apresenta alta participação pelo fato de monitorar o uso dos padrões pelos usuários. Portanto, a maioria dos respondentes não participaram dessa fase, o que evidencia um processo não participativo.

Questionados sobre o acompanhamento do uso do espaço pedagógico, AL respondeu não haver nenhum acompanhamento; TI1 apontou que tem horários estabelecidos pelo Departamento de Ensino para uso do laboratório, mas não mencionou quem faz o acompanhamento; TI2 ressaltou que os alunos não podem fazer uso sem acompanhamento dos professores; e PR explica que durante as aulas ,o monitoramento é feito pelos professores e nos horários de contraturno este acompanhamento é realizado pelo auxiliar de alunos.

\footnotetext{
"Não tem acompanhamento do uso, ou melhor (sic) somos acompanhados pelos professores durante as aulas." (AL).

"Foi definido junto ao departamento de ensino horários disponíveis para alunos em contra turno." (TI1).

"Sei que os alunos podem ter acesso sem o acompanhamento dos professores e nem no horário de aula. Mas sei também que esses dois itens trago de outras instituições de ensino e não de normas que eu tenha visto e grifadas aqui na instituição." (TI2).
}

Interfaces da Educ., Paranaíba, v.11, n.32, p. 79 - 105, 2020 
"Através dos professores durante as aulas ou auxiliar de alunos quando necessário que seja utilizado o laboratório no período que não tenha professor para acompanha-los.” (PR).

\section{Resultados globais do estudo}

Ao analisar, sob a luz do referencial teórico, as formas de participação dos membros de um determinado espaço pedagógico no âmbito da Educação Profissional e Tecnológica da Região Nordeste, com praticamente o mesmo tempo de atuação como integrantes tanto da instituição quanto do espaço pedagógico analisado, obtiveram-se os seguintes resultados com relação as etapas do processo padronização. Estes resultados são: identificação do processo não participativa; elaboração dos padrões não participativa; validação dos padrões não participativa; treinamento para uso dos padrões não participativo; implantação dos padrões semiparticipativa; e acompanhamento do uso dos padrões não participativo.

A partir das evidências empíricas, constata-se que o gerenciamento do espaço pedagógico estudado não é participativo, pois, nem todos os integrantes daquele espaço participam de cada fase do processo de padronização. Para ser considerado como participativo, AL, TI1, TI2 e PR teriam que participar ativamente de todas as fases do processo. Dessa forma, entende-se que poucas pessoas participam e o fazem apenas em relação a algumas etapas do processo de padronização, o que configura o gerenciamento não participativo.

Quadro 5. Resultado do nível de participação de cada respondente da pesquisa

\begin{tabular}{|l|l|l|l|l|c|}
\hline \multicolumn{1}{|c|}{ ETAPA } & TI1 & TI2 & AL & PR & RESULTADO \\
\hline Identificação do processo & Não & Não & Não & Não & Não \\
\hline Elaboração dos padrões & Não & Não & Sim & Sim & Não \\
\hline Validação dos padrões & Não & Não & Não & Não & Não \\
\hline
\end{tabular}

Interfaces da Educ., Paranaíba, v.11, n.32, p. 79 - 105, 2020 


\begin{tabular}{|l|c|c|c|c|c|}
\hline Treinamento & Não & Não & Não & Sim & Não \\
\hline Implantação dos padrões & Não & Não & Sim & Sim & Semiparticipativo \\
\hline Acompanhamento & Não & Não & Não & Sim & Não \\
\hline
\end{tabular}

Fonte: Dados obtidos pelos autores (2019).

A participação pode ser definida como o processo pelo qual os membros de uma organização deliberam e executam ações (KUDO; FERNANDES; SILVA, 2016; LOUSÃO, 2009; FERNANDES, 2015), sem desconsiderar, contudo, as responsabilidades que esses membros precisam ter para com os resultados desse processo. Dessa forma, com relação ao processo de padronização, a participação dos sujeitos no gerenciamento do espaço pedagógico adotado se revelou frágil, dificultando a legitimidade dos padrões adotados. Desde a fase inicial de discussão dos problemas motivadores do processo de padronização, até a etapa final de acompanhamento dos padrões, não houve ampla mobilização da comunidade escolar nas proposituras interventivas.

Em outra direção, um processo de padronização participativo iniciaria com o convite a todos os membros do espaço pedagógico para discutir os problemas decorrentes da falta de padronização e elaborar coletivamente um documento preliminar orientativo para o gerenciamento e a organização do ambiente educativo. Inicialmente, esse documento poderia ser disponibilizado no sítio institucional para que todos os membros tivessem a oportunidade de refazer a leitura e apontar novas sugestões. Após aprimoramento do documento, este passaria para a etapa de validação. Esta fase consiste na participação de todos no processo de deliberação quanto a adoção da proposta.

A continuidade do processo participativo se daria por meio da execução de um cronograma de treinamento para todos os usuários do espaço pedagógico. O treinamento teria como objetivo orientar quanto aos cuidados e procedimentos básicos que cada um deve adotar ao utilizar os Interfaces da Educ., Paranaíba, v.11, n.32, p. 79 - 105, 2020 
equipamentos e compartilhar o espaço de aprendizagem. A implantação do padrão, bem como o acompanhamento de seu uso é uma responsabilidade partilhada por toda a comunidade escolar, portanto, estratégias de gerenciamento participativo e de preservação deverão ser discutidas e negociadas para que se tenha um coletivo organizado e comprometido com os objetivos institucionais. A equipe gestora é a força indutora desse processo de mobilização da comunidade escolar.

\section{Considerações finais}

Este estudo mostrou que o processo de padronização praticado pelos membros do espaço pedagógico observado não pode ser considerado participativo. A participação é percebida como uma prática social que envolve todos os membros de um grupo na tomada de decisão, assim como na execução e responsabilização pelas ações. Assim, para que o processo seja considerado participativo, é imperativo o engajamento de todos os membros de uma organização em todas essas etapas. Os tipos de participação podem ser classificados como não participação, participação moderada e alta participação.

A padronização é o processo que permite estabelecer parâmetros confiáveis para o desenvolvimento satisfatório de uma ação ou procedimento. Os espaços pedagógicos devem utilizar essa ferramenta gerencial para aperfeiçoamento de suas práticas de ensino e alcance de níveis elevados de satisfação. O estudo demonstrou que na organização estudada, de forma geral, o processo de padronização não acontece de forma participativa, visto que todos os respondentes não participaram de cada uma das etapas do processo de padronização, ainda que tenham todos praticamente o mesmo tempo como integrantes do espaço pedagógico. Apenas na fase de implantação dos padrões, identificou-se a participação de mais usuários do espaço pedagógico investigado, que é característica de um processo semiparticipativo. 
Nesse sentido, recomenda-se a discussão coletiva de alternativas que viabilize a participação ativa dos atores escolares em todos os processos de gerenciamento dos espaços pedagógicos. A organização do coletivo em torno de melhores resultados educacionais perpassa pela participação ativa dos indivíduos em todas as etapas de gerenciamento. Esse é um movimento que não acontece de forma espontânea. É preciso que a equipe gestora mobilize a comunidade escolar para o alcance de niveis mais expressivos de envolvimento e de responsabilização.

\section{Referências}

ANDRADE, M.M. A padronização da informação utilizada na composição do perfil socioeconômico das unidades de produção agropecuária de um municipio: uma contribuição à gestão do processo do desenvolvimento agropecuário sustentado. Dissertação (Mestrado em Engenharia de Produção). Universidde Federal de Santa Catarina, Florianópolis, 2004.

CAIXETA, M.C.B.; FABRICIO, M.M. Métodos e instrumentos de apoio ao codesign no processo de projeto de edificios. Ambiente Construído, v.18, n.1, p.111-131, jan/abr. 2018. D.O.I: http://dx.doi.org/10.1590/s1678862120180001212

CARVALHO, A.; RODRIGUES, M. FAP no bairro: uma lógica de desenvolvimento comunitário no Bairro do Carriçal. IS Working Paper, v. 3, n. 63 , p. 1-24, 2018.

DAL FORNO, A. J.; FORCELLINI, F.A.; PEREIRA, F.A.; KIPPER, L.M.; LOOS, M.J. A padronização do processo como primeiro passo para a implementação do desenvolvimento lean de produtos: evidências da indústria têxtil. In: Anais...USABILIDADE EM SISTEMAS INTERATIVOS E ORGANIZACIONAIS. Universidade de Santa Cruz do Sul, Rio Grande do Sul, 24 a 26 de setembro de 2014.

FERNANDES, M. G., Educação ambiental como meio para o

desenvolvimento local: contributo de quatro instituições da região de Bragança. Dissertação (Mestrado em Educação ambiental). Instituto Politécnico de Braganca, Braganca, 2015.

KUDO, S. A; PEREIRA, H. S; SILVA, S. C. P. A proteção jurídica dos fragmentos florestais urbanos: um estudo da paisagem e da legislação ambiental e urbanística da cidade de Manaus. Desenvolv. Meio Ambiente, v. 38, p. 521-540, ago. 2016. DOI: 10.5380/dma.v38i0.42687.

Interfaces da Educ., Paranaíba, v.11, n.32, p. 79 - 105, 2020 
LAPCHAK, P. A.; ZHANG, J. H. Data standardization and quality management. Translational Stroke Research, v. 9, n. 1, p. 4-8, feb. 2018.

LOUSÃO, A. A participação politica e os desafios da inclusão: aspectos normativos da teoria democrática. Diversitates, v. 1, n. 2, p. 28-62, 2009.

MALTA, R. P. D. (Deixem que eu me (Re) Encontre). Projeto de Dissertação (Mestrado em Educação e Intervenção Social). Instituto Politécnico, Porto, 2015.

MOLINÉRO-DEMILLY, V.; CHARKI, A.; JEOFRION, C.; LYONNED, B.; O`BRIEN, S.; MARTIN, L. An overview of quality management system implementation in research laboratory. Int. J. Metrol. Qual. Eng., v. 9, p. 19, fev. 2018. DOI: https://doi.org/10.1051/ijmqe/2017025.

MOSCHIDIS, O.; CHATZIPETROU, E.; TSIOTRAS, G. Quality costing and quality management maturity in Greece: an exploratory multi-dimensional data analysis. International Journal of Productivity and Performance Management, v. 67, n. 1, p. 171-191, 2018. DOI: https://doi.org/10.1108/IJPPM-08-2016-0152

NASCIMENTO-E-SILVA, D. Gestão de organizações de ciência e tecnologia: microensaios sobre a prática do processo gerencial. Saarbrücken: Novas Edições Acadêmicas, 2016.

NASCIMENTO-E-SILVA, D. Manual de redação para trabalhos acadêmicos: position

paper, ensaios teóricos, artigos científicos, questões discursivas. São Paulo: Atlas, 2012.

NASCIMENTO-E-SILVA, D.; SIMÕES, C.S.; SOARES, M.L.; PEREIRA, A.M.A. Proposição de uma sistemática de avaliação da aprendizagem na formação de administradores com base no processo gerencial. Revista de Administração da UFSM; Brazilian Journal of Management, v. 6, n. 4, p. 640-657, dez. 2013. DOI: 10.5902/ 198346595826.

NETTO, A. S.; MEDEIROS, L. M. V. Padronização de processos administrativos: a essência da integração organizacional sob o olhar do profissional de secretariado executivo. Revista do Secretariado Executivo, n. 11 , p. 38-53, 2015.

NYÚL, L. G.; UDUPA, J. K. On standardizating the MR image intensity scale. Magnetic Resonance in Medicine, v. 42, p. 1072-1081, 1999. 
PICCOLI, M.R.; PRADO, G.H. Controle interno municipal: uma análise nas prestações de contas dos municípios do meio oeste catarinense-ANMOC. Gestão \& Sociedade, v.12, n.31, p.2096-2120, 2017. D.O.I: https://doi.org/10.21171/ges.v12i31.2203

RIBEIRO, P. Mobilidade sustentável em arruamentos urbanos e o processo de participação pública (stakeholders). In: ARAÚJO, E.; RIBEIRO, R.; ANDRADE, P.; COSTA, R. (Eds.). Viver em/a mobilidade: rumo a novas culturas de tempo, espaço e distância. Braga: CECS, 2018, p. 95-113.

SABIONI, M.; FERREIRA, M. A.; REIS, A. O. Racionalidades na motivação para a participação cidadã no controle social: uma experiência local brasileira. Cad. EBAPE.BR, Rio de Janeiro, v. 16, n. 1, jan./mar. 2018.

SENGOKU, S.; SUMIKURA, K.; OKI, T.; NAKATSUJI, N. Redefining the concept of standardization for pluripotent stem cells. Stem Cells Review and Reports, v. 7, n. 2, p. 221-226, jun. 2011.

SILVA, R.O.; OLIVEIRA, E.S.; SÁ FILHO, P.; NASCIMENTO-E-SILVA, D. O ciclo PDCA como proposta para uma gestão escolar eficiente. Revista de

Gestão e Avaliação Educacional - REGAE, v.8, n.17, p.1-13, 2019. DOI: http:/ /dx.doi.org/ 10.5902/2318133836102

SOMERS, M. J. Strategies for improving measurement models for secondary data in public administration research: illustration from the federal employee viewpoint survey. Public Administration Review, v. 78, n. 2, p. 228-239, mar/abr. 2018. DOI: https://doi.org/ 10.1111/puar.12805.

TUCZEK, F.; CASTKA, P.; WAKOLBINGER, T. A review of management theories in the context of quality, environmental and social responsibility voluntary standards. Journal of Cleaner Production, v. 176, p. 399-416, mar. 2018. DOI : 10.1016/j.jclepro.2017.12.161.

WIEMES, L.; BALBINOTTI, G. A padronização de processo produtivo em uma indústria automobilística: uma análise teórico prática. Conhecimento Interativo, v.5, n.2, p.84-97, jul/dez. 2011.

ZHU, Y.; WARNER, M. Managing "new generation" employees in China and beyond: summing-up. Asia Pacific Business Review, v. 24, n. 4, p. 578584, mar. 2018. DOI: https://doi.org/10.1080/13602381.2018.1451133. 